\title{
Social distancing and its impact on flattening the COVID-19 curve in Sri Lanka
}

\author{
Sumudu Avanthi Hewage ${ }^{1 *}$, Nuwan Wickramasinghe², Surangi Jayakody ${ }^{3}$, Dulani Samaranayake ${ }^{4}$, \\ Shamini Prathapan ${ }^{3}$, Carukshi Arambepola ${ }^{4}$ \\ ${ }^{1}$ National Program for Tuberculosis Control and Chest Diseases, Ministry of Health, Sri Lanka; ${ }^{2}$ Department \\ of Community Medicine, Faculty of Medicine \& Allied Sciences, Rajarata University of Sri Lanka, Sri Lanka; \\ ${ }^{3}$ Department of Community Medicine, Faculty of Medical Sciences, University of Sri Jayewardenepura, Sri \\ Lanka; ${ }^{4}$ Department of Community Medicine, Faculty of Medicine, University of Colombo, Sri Lanka
}

${ }^{*}$ Correspondence: sumuduavanthi@gmail.com

DOI: https://doi.org/10.4038/jccpsl.v26i1.8314

Received on 09 April 2020

Accepted on 11 April 2020

\section{What is social distancing?}

Social distancing is a non-pharmaceutical intervention that has proven over time to be an effective public health tool in controlling outbreaks that spread from person to person (1). It is implemented by maintaining a minimum recommended physical gap between two persons, so that the infectious agent cannot spread from the infected to non-infected person through droplets, and thereby reduces the number of cases during an outbreak. There are disputes regarding the optimal distance that one should maintain to effectively practice social distancing. Guideline by the Centre for Disease Control recommends a physical distance of 2 metres (2), while the World Health Organization's recommendation is for 1 metre (3).

\section{Public health importance of social distancing}

Social distancing as an intervention is important as it may represent the only type of measure guaranteed to be available against a novel strain of influenza in the early phases of a pandemic (4). According to the evidence thus far, the main mode of transmission of the current COVID-19 outbreak is thought to be droplet transmission. A key goal of counter-acting an epidemic of droplet transmission is to decrease the encounters between the infected individuals and susceptible individuals to decelerate the rate of disease transmission. This holds valid especially for infectious agents which display a higher basic reproduction rate $\left(R_{0}\right)$, which is defined as the number of secondary cases that one case would produce in a completely susceptible population (5).

For the SARS-CoV-2, $\mathrm{R}_{0}$ is predicted to range from 1.4 to 2.5 (6), meaning that one infected person would transmit the virus to 2.5 susceptible persons until the index case becomes symptomatic, gets diagnosed and isolated which is usually taken as 5 days (7). Using this $\mathrm{R}_{0}$, a summation formula is developed to estimate the number of new infections over time, across three scenarios:

- No social distancing practiced

- $50 \%$ of the population practicing social distancing and

- $75 \%$ population practicing social distancing (8)

Accordingly, for COVID-19, the number of persons to whom one infected person can spread the disease at no social distancing is calculated to be 2.5 , 
while for $50 \%$ less exposure due to social distancing, it is 1.25 and for $75 \%$ less exposure due to social distancing, it is 0.625 (Figure 1).

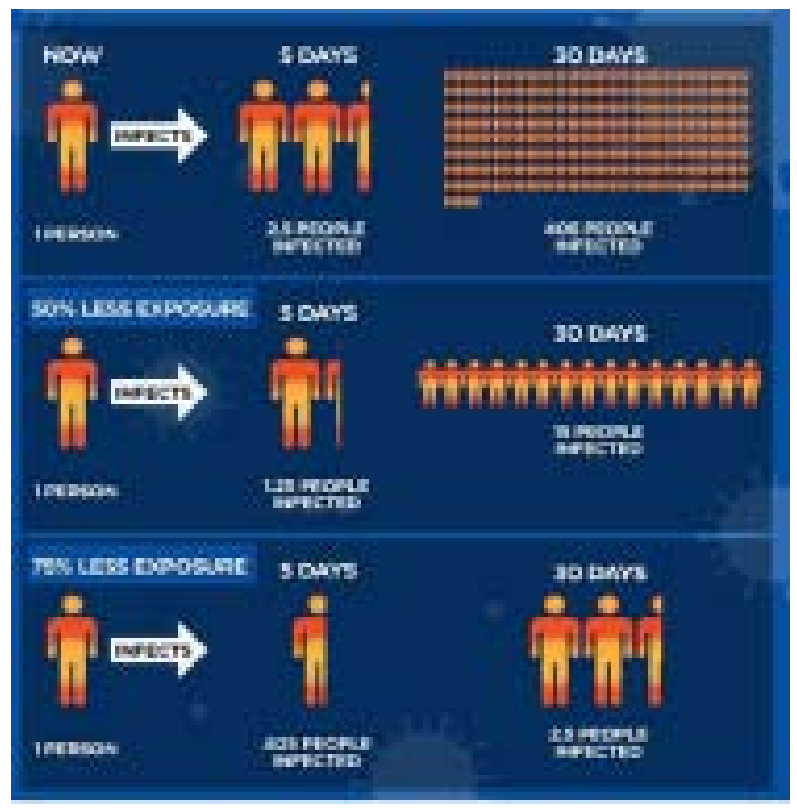

Figure 1. Number of secondary cases generated from a single infected person in three different scenarios of social distancing

Source: Signer laboratory, Social-distancing.com

The assumptions behind the mathematical summation presented by Signer et al. are:

1. $\mathrm{R}_{0}$ to be 2.5

2. An infected individual to spread the virus during the median five-day incubation period before he becomes symptomatic

3. Once symptomatic, the index case to isolate and no longer infect others

4. A linear correlation between social interactions and $\mathrm{R}_{0}$.

\section{Application of social distancing inter- ventions in Sri Lanka}

There are numerous ways one can practise social distancing. These include,

- No handshaking or hugging

- Avoiding crowded settings like marketplaces, public transport and banks
- Avoiding mass gatherings like social events or ceremonial/ religious events

- Maintaining an approximate distance of 6 feet (2 meters) from others

Social distancing invariably means zero touching of other people at all possible times. It is particularly important to maintain the distance from anyone who is having signs of illness, like coughing, sneezing or fever.

On the advice of public health specialists, the government pro-actively took drastic actions to facilitate social distancing interventions among the public to contain the spread of the outbreak in the country. These measures include,

1. Closure of schools (9) and preschools (10)

2. Closure of universities (11)

3. Prohibition of mass gatherings including festivals, sporting events and certain religious activities (12)

4. Closure of social/ leisure settings like cinema (13), zoological/ botanical gardens (14) and museums (15)

5. Declaration of public holidays for the workforce (16)

6. Announcement on 'work from home' period for the public (17)

7. Island-wide curfew (18)

8. Cluster-isolation of some villages (19)

9. Home delivery of essential goods (20)

10. Home delivery of medicines for patients suffering from noncommunicable diseases (21)

National level interventions as given above are vital for ensuring social distancing among people. However, changes in the behaviour at individual level play a key role, especially when most of these interventions are practically difficult to be maintained for long periods of time.

\section{Impact of application of social distancing measures in Sri Lanka}

In Sri Lanka, the first diagnosed local case of COVID-19 was reported on 11 March 2020. As discussed above, social distancing measures were 
implemented immediately after in a cascading manner. Effect of these interventions on the control of the COVID-19 outbreak in Sri Lanka was estimated using Signer's theoretical possibility.

The total number of persons who would develop the infection via the first case reported on 11 March 2020, was estimated up to the period 4 April 2020, under the three scenarios (0\%, 50\% and 75\% social distancing), according to the summation model. Assuming this case became symptomatic 5-days (which is the median incubation period for the disease) after contracting the infection, the number of persons that this case had infected by 11 March would be 2.5. As shown in Figure 2, this number would exponentially increase every 5-days and amount to 406 infected persons by 4 April 2020, if there was no social distancing throughout the period. The corresponding estimates if individuals were practising 50\% and 75\% social distancing measures implemented from the very first case detection would be 15 and 2.5, respectively.
However, Sri Lanka changed this trend promptly by implementing two important public health interventions by 15 March (school, pre-school and university closure and ban on public events, representing around 50\% social distancing) and on 20 March (islandwide curfew representing around 75\% social distancing). The blue line in Figure 2 demonstrates this change in the number infected up to 4 April 2020 via the first case, which is approximately 26, when computed according to the change in $\mathrm{R}_{0}$ following the social distancing measures that were initiated at different time points in Sri Lanka. This may imply that by 4 April 2020, Sri Lanka was able to potentially prevent 380 persons contracting the infection from the index case, through social distancing measures. It should however be noted that these estimates have been drawn only in relation to the index case, while all other cases reported beyond 11 March 2020 had been disregarded; and will invariably be greater when the spread by subsequent cases reported are added according to the summation theory to the total number infected.

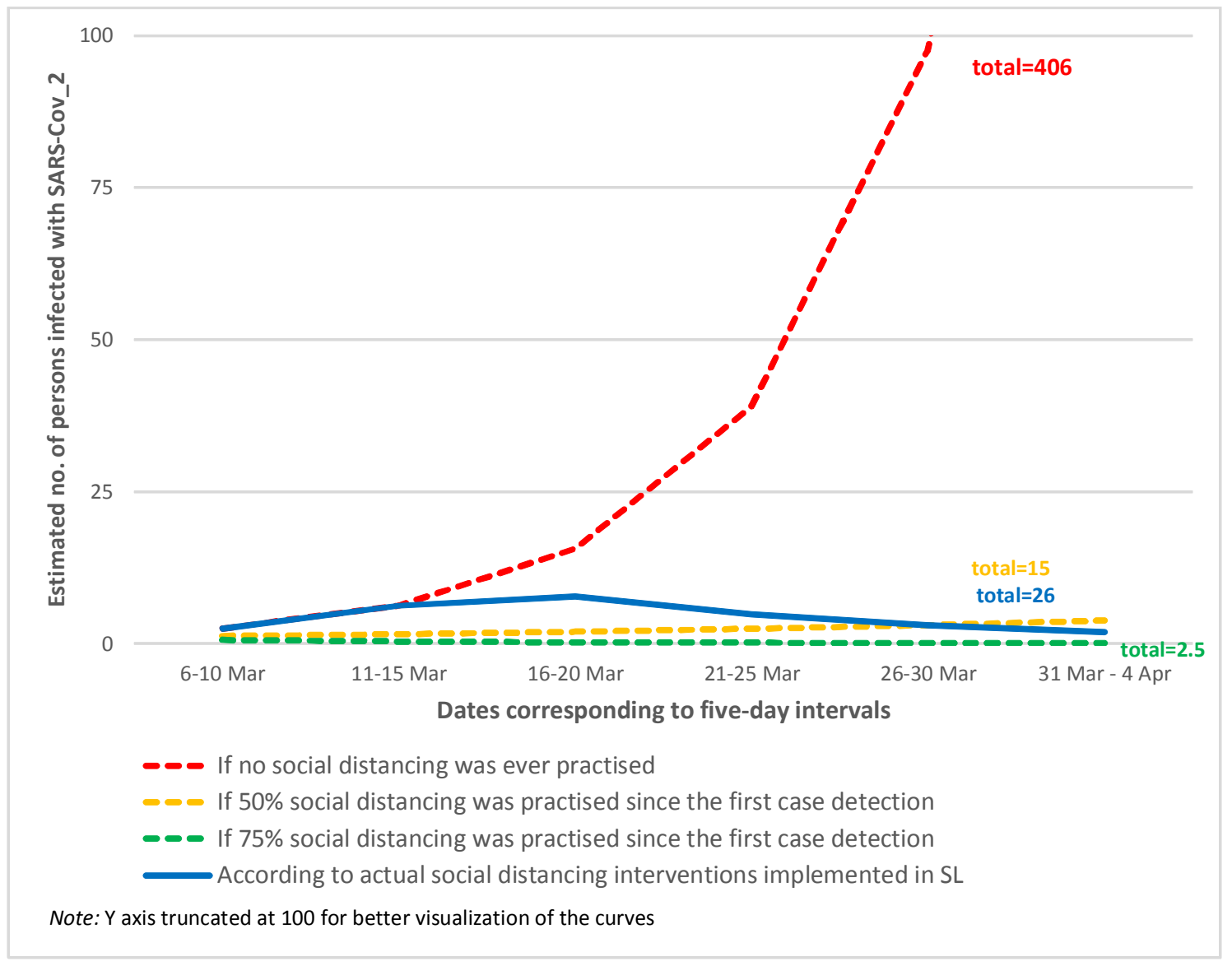

Figure 2. Estimated number of persons infected with SARS-CoV-2 as of 4 April 2020 only by the first local case 
In an attempt to re-calculate these estimates according to the summation theory applied to the subsequent cases as well, Figure 3 shows that the total number who would have been infected by 4 April 2020 would be approximately 8770 , if there was no social distancing. The same estimates if people were practising $50 \%$ and $75 \%$ of social distancing were nearly 867 and 361, respectively. Figure 3 also demonstrates the number estimated to have had the infection by the same date, in relation to the main social distancing events that were implemented in Sri Lanka, which was approximately 637 . When considering the actual number of reported cases of 171 by 4 April 2020, this estimate may imply that only about $25 \%$ of the infected persons have become symptomatic and consequently diagnosed as confirmed cases in Sri Lanka.

These projections give us some clues on the impact of social distancing on the reduction of infected persons in the country. However, these estimates should be interpreted with caution as $\mathrm{R}_{0}$ is well-known to have limited practical value outside the population from which the disease data originate. Further, exact contribution of each intervention to the number prevented is difficult to be determined, all of which could be addressed by robust mathematical modelling. For this purpose, the local evidence on $\mathrm{R}_{0}$ and the average exposure time of individuals to social distancing need to be available. It was therefore assumed that all cases were equally infectious to others during the first five days of being infected (7) and that every case reported was from an independent cluster of contacts. Further, the potential secondary cases were estimated considering the cumulative caseload reported during 5-day interval periods according to the summation assumptions.

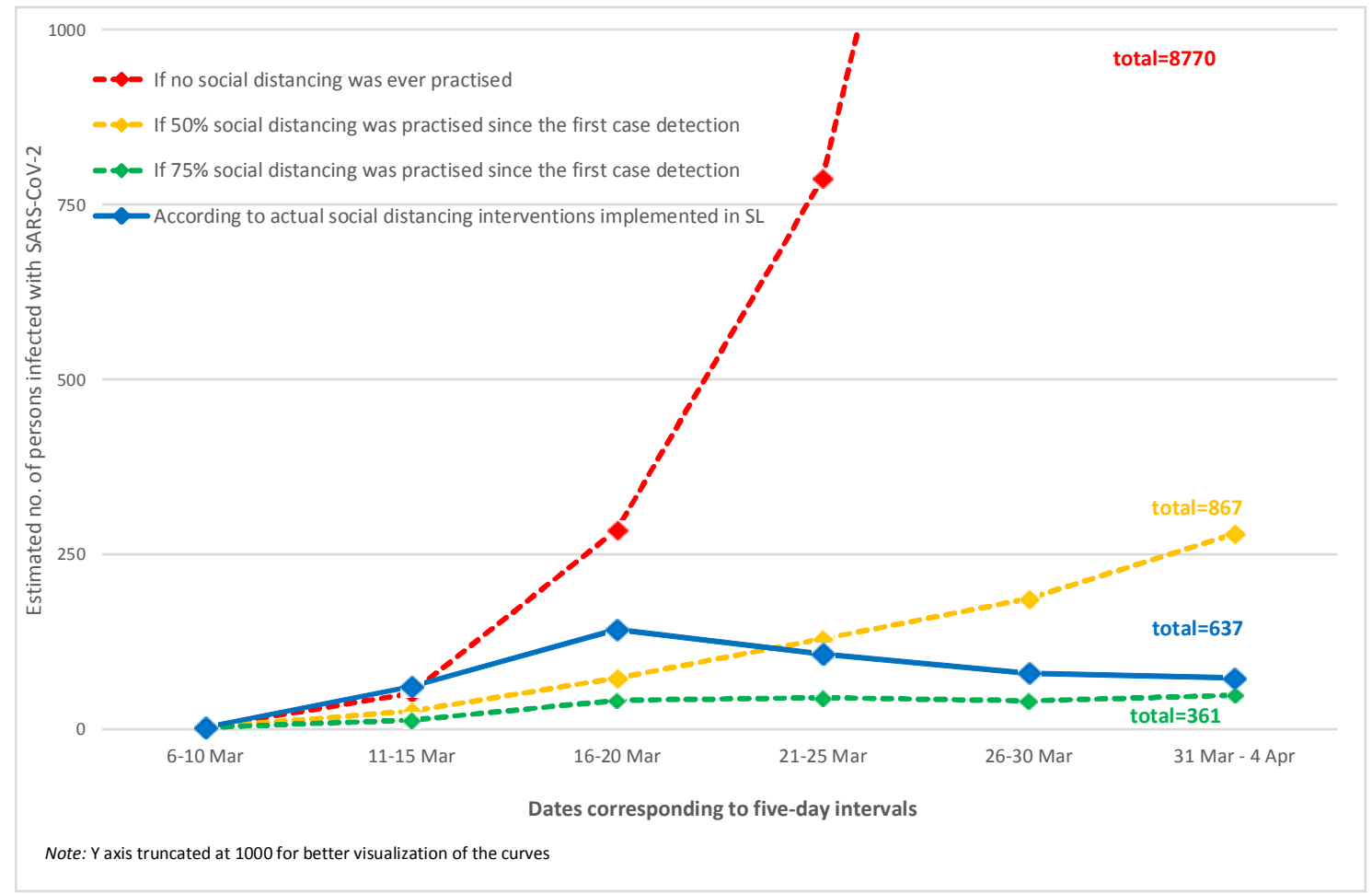

Figure 3. Estimated number of infected persons corresponding to social distancing scenarios and interventions implemented in Sri Lanka 


\section{Gaps in the existing knowledge}

The effectiveness of social distancing depends on many factors. The $\mathrm{R}_{0}$ of the disease in the local context, possible modes of spread of the infectious agent, median incubation period for the disease in the local setting, as well as response of the people to inflicted social distancing measures and probability of change of behaviour at individual level are a few to mention. At global level, evidence is still unclear on the exact mode of spread of the disease to recommend the exact distance to be maintained between two persons to achieve desirable outcomes, resulting in different guideline (2-3). At local level, there are serious gaps in the knowledge even on basic information such as $\mathrm{R}_{0}$ and median incubation period of SARS-CoV-2, due to scarcity of local data.

\section{Recommendations to overcome the challenges in Sri Lanka to contain the outbreak}

Determining the $\mathrm{R}_{0}$ as the epidemic evolves as well as the median incubation period based on local data on confirmed cases of COVID-19 and their contacts, will have major implications in evaluating the applicability of recommended social distancing interventions as well as in planning of other nonpharmaceutical interventions to lower the spread of corona virus infection in Sri Lanka.

Compared to its baseline, Sri Lanka has reported $87 \%, 86 \%$ and $78 \%$ less mobility trends to grocery and pharmacy, to retail and recreation settings (restaurants, shopping centres, libraries and movie theatres etc) and to transit stations (public transport hubs, bus and train stations), respectively (22). However, most social distancing measures executed in Sri Lanka achieved desired results through forced distancing, but not through behaviour change of individuals. Consequently, the threat of all the desirable effects achieved through social distancing taking a U-turn once the national level implementations are lifted persists. Maintaining the effectiveness of social distancing through individual behaviour change remains the biggest challenge faced by public health specialists in Sri Lanka at present. Therefore, novel and effective strategies should be used to educate and promote desirable behaviour changes of the public at individual and family level.

\section{Author Declarations}

Competing interests: The authors declare that they have no conflicts of interests in this study.

Author contributions: SH drafted the manuscript and carried out all the relevant calculations on estimates. $\mathrm{SH}, \mathrm{NW}, \mathrm{SJ}, \mathrm{SP}$ and CA were involved in conceptualization of the study, interpreted the data, and edited the article. DS reviewed and commented on the final draft.

\section{References}

1. Fong MW et al. Non pharmaceutical measures for pandemic influenza in nonhealthcare settings - social distancing measures. Emerg Infect Dis. 2020; published online Feb $6^{\text {th }}$.

https://www.ncbi.nlm.nih.gov/pubmed/32027585

2. Center for Disease Control and Prevention. Public Health Recommendations after Travel-Associated COVID-19 exposure. https://www.cdc.gov/ coronavirus/2019-ncov/php/risk-assessment.html Accessed on $2^{\text {nd }}$ April 2020.

3. World Health Organization. Corona Virus Disease (COVID-19) advice for the public. https://www.who.int/ emergencies/diseases/novel-coronavirus-2019/ advice-for-public Accessed on $2^{\text {nd }}$ April 2020.

4. Kelso JK, Milne GJ \& Kelly H. Simulation suggests that rapid activation of social distancing can arrest epidemic development due to a novel strain of influenza. BMC Pub Heal. 9 (117):2009. https:// bmcpublichealth.biomedcentral.com/articles/10.1186/ 1471-2458-9-117 Accessed 31 ${ }^{\text {st }}$ March

5. Dietz, K. (1993). The estimation of the basic reproduction number for infectious diseases. Statistical methods in medical research, 2(1), 23-41.

6. World Health Organization. Corona Virus Disease 2019 (COVID-19). Situation report 46. 06th March 2020. https://www.who.int/docs/default-source/ coronaviruse/situation-reports/20200306-sitrep-46covid-19.pdf?sfvrsn=96b04adf_2 Accessed on 30 ${ }^{\text {th }}$ March 2020.

7. Lauer SA, Grantz KH, Bi Q, et al. 10 March 2020. The incubation period of coronavirus disease 2019 (COVID19) from publicly reported confirmed cases: Estimation and application. Ann Int Med 2020. DOI:10.7326/M200504 https://annals.org/aim/fullarticle/2762808/ 
incubation-period-coronavirus-disease-2019-covid-19from-publicly-reported Accessed 27 ${ }^{\text {th }}$ March 2020

8. Signer AJR et al. 2020.Coronavirus and social distancing. http://social-distancing.com/ Accessed 29 ${ }^{\text {th }}$ March 2020

9. Lanka Education.com. All schools in Sri Lanka closed due to Coronavirus. March 12th 2020. https:// www.lankaeducation.com/all-schools-closed-in-srilanka-due-to-coronavirus/ Accessed on April $1^{\text {st }} 2020$

10. Daily Mirror. All pre-schools to be closed from today. March 13th 2020. http://www.dailymirror.lk/ breaking_news/All-pre-schools-to-be-closed-fromtoday/108-184923 Accessed April $1^{\text {st }} 2020$

11. Lanka Education.com. All universities closed in Sri Lanka due to Coronavirus precautionary measures. March 13th 2020. https://www.lankaeducation.com/alluniversities-closed-in-sri-lanka-due-to-coronavirusfear/ Accessed April $1^{\text {st }} 2020$

12. Sri Lanka Weekly. Sri Lanka bans public events as coronavirus cases rise to eight. March $14^{\text {th }}$. https:// www.srilankaweekly.co.uk/sri-lanka-bans-publicevents-coronavirus-cases-rises-eight/ Accessed April $2^{\text {nd }} 2020$

13. NEWS RADIO.lk. COVID-19: Cinemas closed until further notice. https://www.newsradio.lk/trending/ covid-19-cinemas-closed-until-further-notice/ Accessed April $1^{\text {st }} 2020$

14. Sri Lanka Breaking News. Zoo, botanical gardens and national parks closed. March $14^{\text {th }}$ 2020. http:// srilankabreakingnews.com/2020/03/14/zoo-botanicalgardens-and-national-parks-closed/ Accessed April $2^{\text {nd }} 2020$
15. Daily News. All museums closed until further notice. March 16 ${ }^{\text {th }}$ 2020. https://www.dailynews.lk/2020/03/16/ local/214557/all-museums-closed-until-further-notice Accessed April $2^{\text {nd }} 2020$

16. Colombo Page. Sri Lanka Government declares 3-day special public holiday to contain coronavirus spread. March 14 $4^{\text {th }}$ 2020. http://www.colombopage.com/ archive_20A/Mar17_1584386009CH.php Accessed April $1^{\text {st }} 2020$

17. News First.lk. March 20-27 ${ }^{\text {th }}$ declared a work from home period. 19 $9^{\text {th }}$ March 2020. https://www.newsfirst.lk/2020/ 03/19/20-27-march-declared-a-work-from-home-period/ Accessed April $2^{\text {nd }}$

18. 60-hour Island-wide curfew due to COVID-19. $20^{\text {th }}$ March 2020. http://colombotimes.net/60-hourislandwide-curfew-from-6-pm-on-friday-due-to-covid19/

19. Ada derana. Atalugama sealed off. 28 $8^{\text {th }}$ March 2020. http://www.adaderana.1k/news.php?mode= head\&nid=3813 Accessed $3^{\text {rd }}$ April 2020

20. Read Me. COVID-19 Social distancing \& options for home-delivered groceries in Sri Lanka. 28 ${ }^{\text {th }}$ March 2020. https://www.readme.lk/covid-19-home-deliveredgroceries/ Accessed $3^{\text {rd }}$ April 2020

21. Colombo Page. Arrangements made to home-deliver medications. 27 $7^{\text {th }}$ March 2020. http://www. colombopage.com/archive_20 A/Mar27_ 1585333269CH.php Accessed $3^{\text {rd }}$ April 2020

22. Google COVID-19 Community Mobility Report. $29^{\text {th }}$ March 2020. https://www.gstatic.com/covid19/ mobility/2020-03-29_LK_Mobility_Report_en.pdf Accessed $1^{\text {st }}$ April 2020 